\title{
DIAGNÓSTICO QUANTIQUALITATIVO DE LIXO PATOGÊNICO NO HOSPITAL REGIONAL DE CATOLÉ DO ROCHA-PB
}

\author{
DIAGNÓSTICO QUANTIQUALITATIVE DE BASURA PATÓGENA EN HOSPITAL \\ REGIONAL CATOLÉ DE ROCHA-PB
}

\section{QUANTIQUALITATIVE DIAGNOSISOFGARBAGE IN HOSPITAL PATHOGENIC REGIONAL DECATOLÉ DO ROCHA-PB}

\author{
Francisco Edimilcio Maia NETO ${ }^{1}$ \\ José Sebastião MELO FILHO ${ }^{2}$ \\ Thiago Pereira SOUSA ${ }^{3}$ \\ Luís Alberto Silva ALBUQUERQUE ${ }^{4}$ \\ Fabiana Xavier COSTA ${ }^{5}$
}

RESUMO: Objetivou-se com este trabalho fazer um levantamento quantiqualitativo do lixo patogênico do Hospital Regional Dr. Américo Maia de Vasconcelos localizado na cidade de Catolé do Rocha - PB. A pesquisa foi realizada no período de 01/05/2012 à 31/05/2012, onde envolveu toda a comunidade hospitalar, tais como: auxiliares e técnicos de enfermagem, enfermeiros, técnico de raio-x, assistente social, médicos, arquivistas e faturistas, digitadores, fisioterapeutas, nutricionistas, porteiro e maqueiro e auxiliar de serviços gerais e jardineiros, desde a coleta até a pesagem diária destes resíduos que apresenta alto risco para os seres humanos e o meio ambiente, durante o mês da pesquisa na unidade observou-se enorme preocupação da administração com todos os funcionários, inclusive os que têm acesso ao lixo. A pesagem da primeira semana obteve $228,5 \mathrm{Kg}$, Na segunda semana foi constatado $381 \mathrm{Kg}$, observou-se na terceira semana uma redução de $307 \mathrm{Kg}$, já na quarta semana obteve aumento de $410 \mathrm{Kg}$ e na quinta semana diminui para $151 \mathrm{Kg}$ de lixo infectante (seringas, agulhas, ataduras, gases, cateteres, sondas, curativos e materiais de coleta de exames). Obtendo um total de $1.477,5 \mathrm{Kg}$. No período da pesquisa constatou-se que os municípios do sertão paraibano, em especial Catolé do Rocha necessitam de incineradores ambientalmente corretos, pois o lixo coletado no hospital é levado para a capital João Pessoa - PB, a uma distância de mais de $500 \mathrm{~km}$, onde são incinerados os resíduos sólidos gerados na unidade de saúde.

Palavras-chave: meio ambiente, resíduos sólidos, contaminação

\footnotetext{
${ }^{1}$ Universidade Estadual da Paraíba - UEPB. Departamento de Agrárias e Exatas, Curso Licenciatura Plena em Ciências Agrárias. edimilcio_maia@hotmail.com

${ }^{2}$ Universidade Federal de Campina Grande - UFCG. sebastiaouepb@ yahoo.com.br

${ }^{3}$ Universidade Estadual da Paraiba - UEPB, Departamento de Agrárias e Exatas Licenciatura Plena em Ciências Agrárias tiagojd2009@hotmail.com

${ }^{4}$ Universidade Estadual da Paraiba - UEPB, Departamento de Agrárias e Exatas, Curso Licenciatura Plena em Ciências Agrárias luisalbuquerque26@hotmail.com

${ }^{5}$ Doutorado em recursos naturais. Universidade Estadual da Paraíba - UEPB. fabyxavierster@ gmail.com
} 
RESUMEN: El objetivo de este trabajo fue realizar un estudio de la basura cuanti patógena Regional Hospital Dr. Américo Maia de Vasconcelos situado en el Catolé Rocha - PB. La encuesta se realizó del 01/05/2012 al 31/05/2012, que involucró a toda la comunidad hospitalaria, tales como auxiliares de enfermería y técnicos, enfermeras, técnicos de rayos $\mathrm{x}$, trabajadores sociales, médicos, archiveros y faturistas, mecanógrafos, fisioterapeutas, nutricionistas, portero y conserje y asistente y jardineros en general, desde la recolección hasta el pesaje diario de este tipo de residuos, que tiene un alto riesgo para los seres humanos y el medio ambiente, durante el mes de la encuesta de la unidad observada gran preocupación de la administración con todos los empleados, incluidos los que tienen acceso a la basura. El pesaje 228,5 kg se obtuvo primera semana, la segunda semana se observó $381 \mathrm{~kg}$, se observó una reducción en la tercera semana de $307 \mathrm{~kg}$, tal como se obtiene en la cuarta semana, y aumentaron a $410 \mathrm{~kg}$ en la quinta semana disminuye a 151 libras de basura infecciosos (jeringas, agujas, vendas, gases, catéteres, sondas, materiales curativos y recogida de muestras). Conseguir un total de 1,477.5 Kg Durante la investigación se comprobó que los municipios de Paraíba interior, especialmente la Catolé do Rocha requieren incineradores ecológicos ya que la basura recolectada es llevada al hospital de la capital João Pessoa - PB, a una distancia de más de $500 \mathrm{~km} / \mathrm{h}$, que se incineran los residuos sólidos generados en la unidad de salud.

Palabras clave: medio Ambiente, los residuos sólidos, contaminación

\begin{abstract}
The objective of this work was to survey quanti garbage pathogenic Regional Hospital Dr. Americo Maia de Vasconcelos located in Catolé do Rocha - PB. The survey was conducted in the period from 01/05/2012 to 31/05/2012, which involved the entire hospital community, such as nursing assistants and technicians, nurses, $\mathrm{x}$-ray technician, social worker, medical, archivists and faturistas, typists, physiotherapists, nutritionists, doorman and porter and general assistant and gardeners, from collection to the daily weighing of these residues that presents a high risk to humans and the environment during the month of the survey on unit observed huge concern of administration with all employees, including those who have access to garbage. The weighing $228.5 \mathrm{~kg}$ was obtained first week, the second week $381 \mathrm{~kg}$ was found, there was a reduction in the third week of $307 \mathrm{~kg}$, as obtained in the fourth week, and increased to $410 \mathrm{~kg}$ on the fifth week decreases to $151 \mathrm{~kg}$ of garbage infective (syringes, needles, bandages, gases, catheters, probes, dressings and materials sample collection). Getting a total of $1,477.5 \mathrm{~kg}$ During the research it was found that the municipalities of the interior of Paraiba, especially the Catole do Rocha incinerators require environmentally friendly because the waste collected is taken to hospital in the capital João Pessoa - PB, at a distance of more de $500 \mathrm{~km} / \mathrm{h}$, which is incinerated solid waste generated in the health unit.
\end{abstract}

Keywords: environment, waste solids, contamination

\title{
INTRODUÇÃO
}


O lixo hospitalar tem grande risco de contaminação que prejudica os seres humanos e o meio ambiente, totalmente diferente dos outros tipos de lixo, merece cuidado especial desde sua coleta até a incineração. Nos aterros sanitários, trata-se de seringas, agulhas, ataduras, gases, cateteres, sondas, curativos e materiais de coleta de exames, entre outros (lixo patogênico).

Considerando que os sistemas de tratamento térmico de resíduos são fontes potenciais de risco ambiental e de emissão de poluentes perigosos que constitui agressão à saúde e meio ambiente se não forem corretamente instalados, operados e mantidos pela (CONAMA et al. 2012).

Diversos problemas ambientais existentes mundialmente, o dos resíduos sólidos urbanos torna-se um dos maiores desafios da atualidade. Através do acelerado avanço tecnológico e o crescimento habitacional ocorrem incremento na produção de bens e serviços. Entretanto, à medida que são produzidos e consumidos, acarretam uma geração cada vez maior de resíduos, os quais, quando dispostos inadequadamente, trazem significativos impactos à saúde pública e ao meio ambiente.

De acordo com Guerra et al. (2009) os riscos ambientais são resultantes da associação de riscos decorrentes de processos naturais agravados pelas atividades humanas e pela ocupação do território.

A alta produção de resíduos sólidos, a destinação inadequada destes constitui fator preocupante, pois constitui para a poluição do solo, do ar e dos lençóis freáticos. A maior parte dos resíduos sólidos produzidos é de caráter orgânico, tais como: restos de comida, cascas de frutas e verduras, sementes, além de folhas e galhos de árvores provenientes de poda, dentre outros estudos realizados por (Silva et al; 2010).

Segundo Besen et al. (2010) a gestão e disposição inadequada dos resíduos sólidos causam impactos socioambientais, tais como: degradação do solo, comprometimento dos corpos d'água e mananciais, intensificação de enchentes, contribuição para poluição do ar e proliferação de vetores de importância sanitária nos centros urbanos e catação em condições insalubres nas ruas e nas áreas de disposição final.

Princípio de precaução e sustentabilidade significa impulsionar mudanças e adotar atitudes precavidas, sustentáveis. Todavia, o alcance destes objetivos, só será possível por meio de um processo contínuo e permanente de educação ambiental, constituindo um processo educativo que ocorre a partir da realidade ambiental, buscando a construção de 
conhecimento, compreensão das leis naturais, mudanças de percepção e de valores, soluções e ações sustentáveis (SILVA et al., 2009).

O Brasil conta com um marco para a criação de possíveis iniciativas públicas com relação aos resíduos sólidos, a Lei de Saneamento Básico. A Política Nacional de Resíduos Sólidos, disciplina a coleta, o destino final e o tratamento de resíduos urbanos, perigosos e industriais, entre outros, além de estabelecer que os estados e municípios têm até agosto de 2012 para elaborar seus Planos de Resíduos Sólidos e continuar ter acesso aos recursos do Governo Federal, na área de resíduos e que os mesmos possuem o período de agosto de 2014 para eliminar lixões e implantar aterros sanitários, que receberão apenas rejeitos.

A Paraíba está entre os estados que pior tratam os resíduos sólidos, cerca de $70 \%$ do lixo é jogado em lixões, excetuando a cidade de João Pessoa que possui um aterro sanitário (ALCÂNTARA, 2011).

De acordo com Bravo (2011) a educação ambiental crítica tem como ponto de partida o real concreto dos sujeitos e embalada por ideais democráticos e participativos, visando contribuir para mudança de valores e atitudes frente ao mundo, tornando como palco de relações socioambientais em disputa, em construção. Através da conscientização, sensibilização e reflexão, a educação deve ser vista como uma possibilidade de mudança das relações sociais, de edificação de valores mais solidários e de valorização de práticas contrárias a competição exacerbada e ao consumo desmedido (LOPES; SOSSAE, 2010).

De acordo com as normas da resolução do CONAMA pode perceber que no hospital regional de Catolé do Rocha - PB constata-se um órgão interno responsável por mostrar aos funcionários vários riscos que o lixo tem pela comissão de controle de infecção hospitalar $(\mathrm{CCIH})$, responsável pelas medidas que ensinar e fiscalizar de forma padronizada a maneira correta, onde é feito o controle da coleta do lixo hospitalar, por tanto essa realidade é muito preocupante.

Tendo em vista o descaso com os resíduos sólidos por parte dos governos municipais, estaduais e federais no Brasil e no mundo, especialmente com os resíduos patogênicos, fez-se necessário a realização dessa pesquisa, para averiguar a quantidade, qualidade e se os resíduos patogênicos do Hospital Regional Dr. Américo Maia de Vasconcelos localizado no município de Catolé do Rocha - PB tem destino final ecologicamente correto como manda a lei, pelo fato de se tratar de resíduos altamente perigosos pra saúde dos seres vivos, inclusive humanos e ameaçado meio ambiente. 
Objetivou-se com esta pesquisa realizar um levantamento quantiqualitativo do lixo patogênico produzido no Hospital Regional Dr. Américo Maia de Vasconcelos, localizado no município de Catolé do Rocha - PB, visando analisar a quantidade e qualidade lixo produzido nesta unidade de saúde, utilizando como ferramenta de sensibilização o processo de educação ambiental, onde envolveu toda a comunidade do hospital, no intuito de expandir o interesse de todos, principalmente para o desenvolvimento sustentável e melhorar a qualidade de tratamento do lixo desde a coleta até seu destino final ecologicamente correto.

\section{MATERIAIS E MÉTODOS}

A pesquisa foi realizada no município de Catolé do Rocha - PB, localizado no sertão paraibano, com uma população, de acordo com o IBGE (2010), de 28.766 habitantes (Figura 1). Possui área territorial de 552, $098 \mathrm{Km}^{2}$, coordenadas geográficas está situada na região do baixo sertão do piranhas a $6^{\circ} 20^{\prime} 38^{\prime \prime}$ de Latitude Oeste e $37^{\circ} 44^{\prime} 48^{\prime \prime}$ de Longitude Sul. Sua altitude em relação ao nível do mar é de 275 metros. O projeto foi realizado no hospital regional Dr. Américo Maia de Vasconcelos, localizado na Rua Castelo Branco, S/N, centro da cidade. Sua estrutura física está em bom estado de conservação estando entre um dos melhores hospitais e atendendo a população de Catolé do Rocha-PB e toda região metropolitana. (Figura 2 A e B).

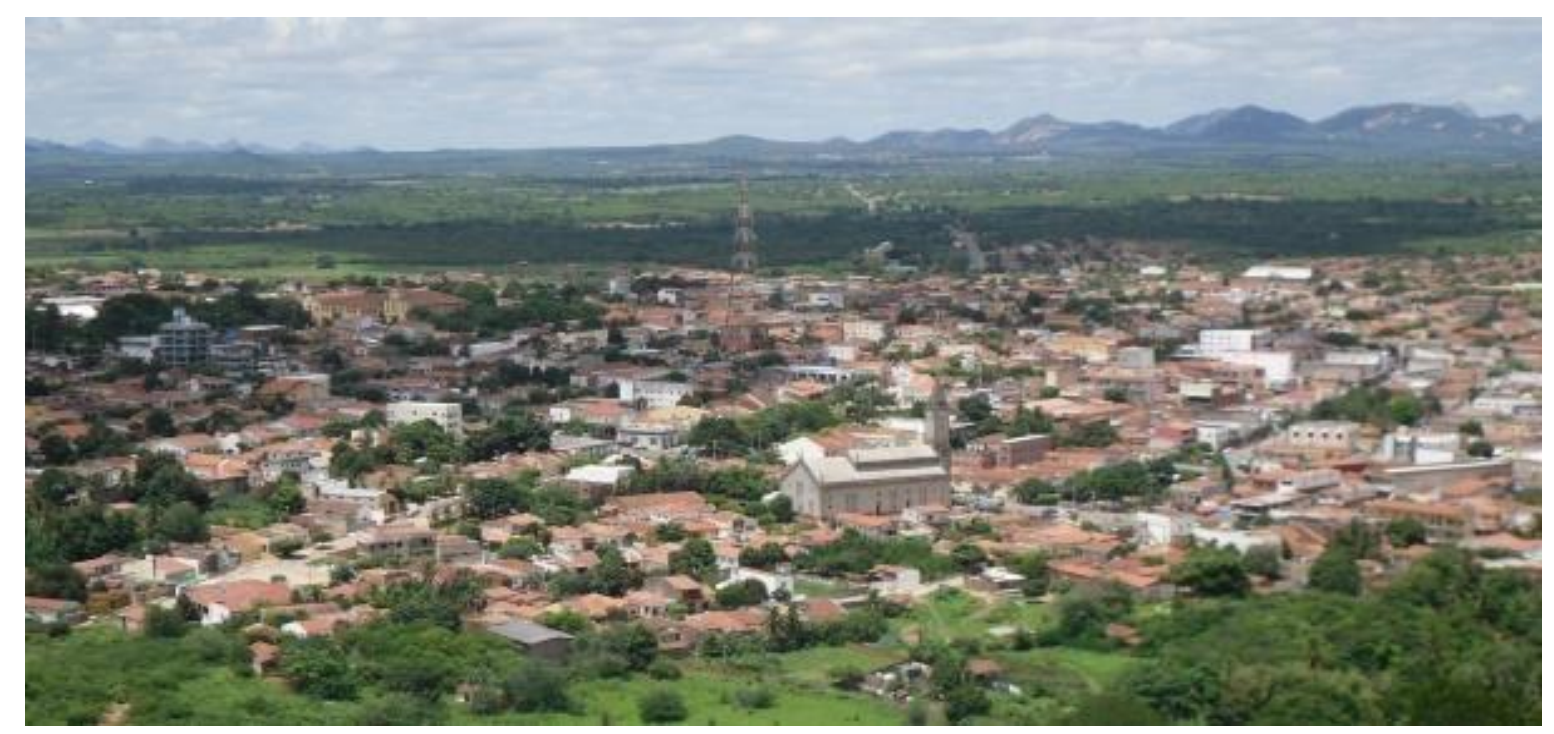

Figura 1: Imagem da cidade de Catolé do Rocha - PB. 

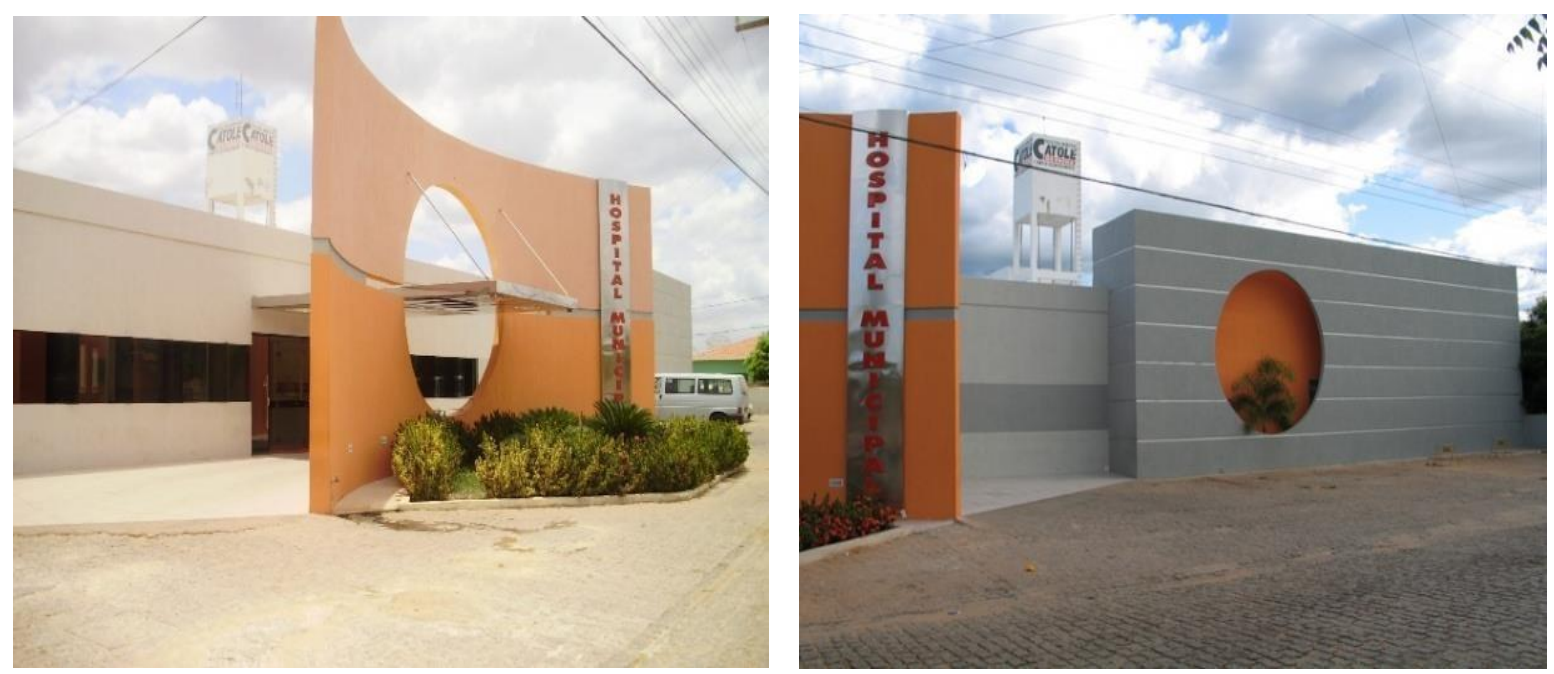

Foto: Francisco Edimilcio Maia Neto

Figura 2: Hospital Regional de Catolé do Rocha-PB (A e B).

A unidade funciona com um grande quadro de funcionários como: 21 auxiliares e técnicos de enfermagem, 20 enfermeiros, 06 técnicos de raio-x, 04 assistente social, 17 médicos,03 farmacêuticos e 02 auxiliares de farmácia,04 fisioterapeutas, 02 nutricionistas, 01 jardineiro,06 motoristas, 05 porteiros e 05 maqueiros, 14 auxiliares de serviços gerais,07 recepcionistas, 01 artífice, 02 digitadores,04 faturistas, 01 arquivista, 02 financeiro, 01 diretor, 01 recursos humanos, 01 administrador, um total de 130 funcionários. O trabalho foi desenvolvido no período de 01/05/2012 a 31/05/2012, foi feito o acompanhamento da coleta e pesagem do lixo diariamente, procuramos saber da direção para onde jogava todo o lixo patogênico do hospital, ficamos sabendo que o mesmo é levado para um aterro sanitário onde é devidamente incinerado, o transporte é feito, através de um veiculo preparado e bem fechado (carro fogão), e esse trabalho é feito somente nas unidades de saúde do estado, o que é de grande preocupação, porque já sabemos o destino correto do lixo patogênico do hospital regional, e as outras unidades da cidade e de municípios vizinhos, com isso existe uma grande necessidade de um aterro sanitário com urgência na região.

Para começar a pesquisa foi feito uma cartilha mostrando os danos do lixo patogênico, essa cartilha foi distribuída principalmente para os funcionários que trabalha diretamente com o lixo hospitalar da unidade. É uma pesquisa capaz de identificar os danos que o lixo tem se não fossem corretamente tratados, riscos esses não somente com o ser humano mais com o meio ambiente. A pesquisa foi feita diariamente no hospital regional, com acompanhamento da pesagem realizada todos os dias úteis da semana (Figuras $3 \mathrm{~A}, \mathrm{~B}$ e $\mathrm{C}$ ). 

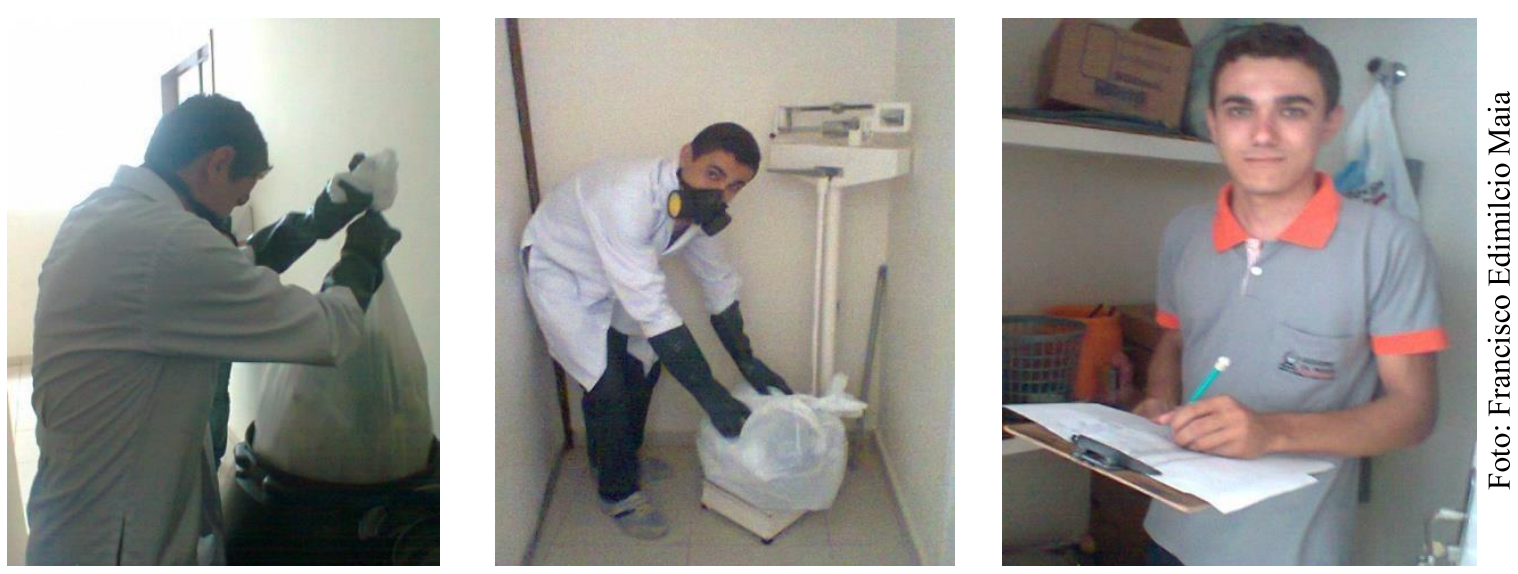

Figura 3: Retirada do lixo para pesagem (A). Realização da pesagem do lixo (B) e fazendo anotações das análises $(\mathrm{C})$.

Para o desenvolvimento da pesquisa foi utilizado luvas longas de borracha, máscara com filtros e jaleco, todos fornecidos pela unidade de saúde citada.

\section{RESULTADOS E DISCUSSÃO}

Podemos perceber que os resíduos perfurocortantes produzidos no Hospital Regional Dr. Américo Maia de Vasconcelos em Catolé do Rocha - PB, possui destino correto, todo lixo produzido na unidade de saúde é disposto em caixas e sacos que são aprovadas pelo INMENTRO (Instituto Nacional de Metrologia, Qualidade e Tecnologia), onde são espalhados em vários setores como posto de atendimento interno, enfermarias, sala de vacina, esterilização, sala de parto, bloco cirúrgico, urgência e emergência entre outros, esse lixo é coletado diariamente no final de cada expediente de trabalho, por se trata de um hospital de muitos atendimentos, geralmente são utilizadas a troca das caixas duas vezes ao dia, pela manhã e no final da tarde, logo depois de coletado o lixo fica disposto em tambores de borracha e bem vedados, até que os coletores venha buscá-lo, a coleta foi feita duas vezes no mês por coletores que deslocava da capital João Pessoa - PB, em um veiculo tipo caminhão fogão, onde o lixo é levado em destino correto para incineração.

O destino do lixo produzido no hospital regional não é preocupante, mais outras unidades de saúde da cidade e de municípios vizinhos não sabemos como é feita à coleta, pois se trata de órgãos municipais em que o estado não tem compromisso de fazer coleta, o ideal seria a construção de um aterro sanitário na região de Catolé do Rocha - PB, por se tratar de ser sede da $8^{\text {a }}$ região da Paraíba, onde várias cidades são polarizadas. 
Os resultados obtidos nas pesagens semanais encontram-se nas tabelas, onde tivemos valores correspondentes em comparação a outros trabalhos.

De acordo com os dados da tabela 1, os resíduos do grupo A (risco biológico), foram mais produzidos compreendendo um percentual de 53,9\%. Esses materiais são de grande risco para os humanos e meio ambiente devido a presença de agentes biológicos, como materiais cirúrgicos e sangue. Esses resíduos devem ser acondicionados em sacos plásticos resistentes e identificados simbologia infectante. Já o grupo E apresentou um percentual de $46 \%$, esses materiais são de risco por se tratar de lixo cortante como agulhas, bisturi entre outros, esses devem ser descartados separadamente.

Tabela 1 - Produção de Resíduos Sólidos de Saúde gerados no Hospital Regional Dr. Américo Maia de Vasconcelos- Catolé do Rocha - PB, levando em consideração os resíduos do grupo A (risco biológico) e grupo E (perfuro cortantes) primeira semana. UEPB, Catolé do Rocha - PB, 2014.

\begin{tabular}{c|c|c}
\hline Magnitude & Kg/semana & $\begin{array}{c}\text { Porcentagem } \\
\text { (\%) }\end{array}$ \\
\hline Parâmetro & & 53,9 \\
Grupo A & 123,3 & 46 \\
\hline TOTAL E & 105,2 & 100 \\
\hline
\end{tabular}

Analisando os dados expostos na tabela 2, verifica-se que o resíduo mais gerado na segunda semana foi o do grupo A com um percentual de 60,6\%. De acordo com Brito (2000), os resíduos que apresentam risco biológico são submetidos a tratamento até seu destino final por se tratar de materiais muito perigosos. 
Tabela 2 - Produção de Resíduos Sólidos de Saúde gerados no Hospital Regional Dr. Américo Maia de Vasconcelos- Catolé do Rocha - PB, levando em consideração os resíduos do grupo A (risco biológico) e grupo E (perfuro cortantes) segunda semana. UEPB, Catolé do Rocha - PB, 2014.

\begin{tabular}{c|c|c}
\hline Magnitude & Kg/semana & $\begin{array}{c}\text { Porcentagem } \\
\text { (\%) }\end{array}$ \\
\hline Parâmetro & & 60,6 \\
Grupo A & 230,9 & 39,3 \\
\hline TOTAL & 150,1 & 100 \\
\hline
\end{tabular}

Verificando os dados da tabela 3, constatam-se mais uma vez que o material do grupo A gerados na unidade de saúde na terceira semana foi o mais produzido com um percentual de $55,8 \%$.

Tabela 3 - Produção de Resíduos Sólidos de Saúde gerados no Hospital Regional Dr. Américo Maia de Vasconcelos- Catolé do Rocha - PB, levando em consideração os resíduos do grupo A (risco biológico) e grupo E (perfuro cortantes) terceira semana. UEPB, Catolé do Rocha - PB, 2014.

\begin{tabular}{c|c|c}
\hline Magnitude & Kg/semana & $\begin{array}{c}\text { Porcentagem } \\
\text { (\%) }\end{array}$ \\
\hline Parâmetro & & 55,8 \\
Grupo A & 171,6 & 44,1 \\
\hline TOTAL & 135,4 & 100 \\
\hline
\end{tabular}

Examinando os resultados da tabela 4, observa-se que na quarta semana do mês foi a que mais produziu material do grupo A e E, chegando a um valor total de $410 \mathrm{Kg}$ de material produzido na unidade.

Os resíduos do grupo A apresentaram um percentual de 55,1\% esse material apresenta grande risco, o material do grupo E obteve um percentual de $44,8 \%$ de lixo perfuro-cortante. 
Tabela 4 - Produção de Resíduos Sólidos de Saúde gerados no Hospital Regional Dr. Américo Maia de Vasconcelos- Catolé do Rocha - PB, levando em consideração os resíduos do grupo A (risco biológico) e grupo E (perfuro cortantes) quarta semana .UEPB, Catolé do Rocha - PB, 2014.

\begin{tabular}{c|c|c}
\hline Magnitude & Kg/semana & $\begin{array}{c}\text { Porcentagem } \\
\text { (\%) }\end{array}$ \\
\hline Parâmetro & 226 & 55,1 \\
Grupo A & 184 & 44,8 \\
\hline TOTAL & & 100 \\
\hline
\end{tabular}

Avaliando os dados da tabela 5, que corresponde a quinta semana do mês foi a que menos produziu material, chegando a um valor total de $151 \mathrm{Kg}$ de lixo produzido na unidade, o grupo A obteve um percentual de 63,1\%, e o do grupo E, $36,8 \%$.

Tabela 5 - Produção de Resíduos Sólidos de Saúde gerados no Hospital Regional Dr. Américo Maia de Vasconcelos- Catolé do Rocha - PB, levando em consideração os resíduos do grupo A (risco biológico) e grupo E (perfuro cortantes) quinta semana. UEPB, Catolé do Rocha - PB, 2014.

\begin{tabular}{c|c|c}
\hline Magnitude & Kg/semana & $\begin{array}{c}\text { Porcentagem } \\
\text { (\%) }\end{array}$ \\
\hline Parâmetro & & 63,1 \\
Grupo A & 95,3 & 36,8 \\
\hline TOTAL & 55,7 & 100 \\
\hline
\end{tabular}

De acordo com dados expostos nas tabelas chegamos a um valor total de $1.447,5 \mathrm{Kg}$ de lixo do grupo A e E produzidos no Hospital de Catolé do Rocha-PB, lembrando que os materiais de risco radioativo não ficam na unidade são levados para João Pessoa - PB, onde lá são apresentados a médicos para ser realizados laudos médicos, já o lixo comum produzido e coletado pela prefeitura diariamente. 
Os resultados apresentados no gráfico 1 confirmam que a unidade de saúde produzem 1.477,5 $\mathrm{Kg}$ de lixo do grupo A e E, isto é, se não fosse descartado corretamente poderiam produzir grandes impactos a sociedade e meio ambiente.

Podemos comprovar que na quarta semana obteve um valor de $28 \%$ do lixo coletado no hospital regional durante o mês de maio de 2012.

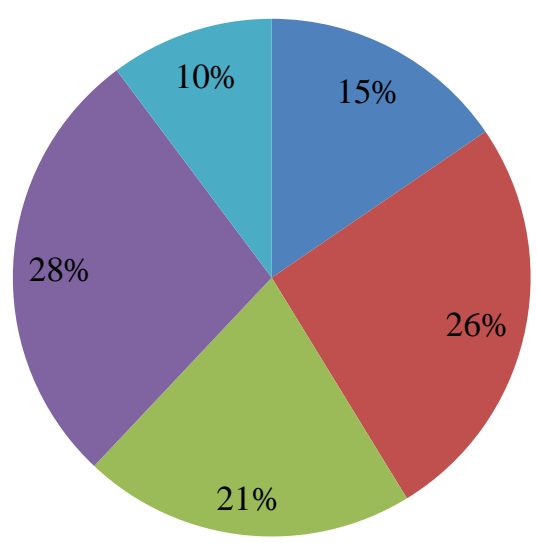

$$
\begin{aligned}
& 1^{a} \text { semana } \\
& 2^{a} \text { semana } \\
& 3^{a} \text { semana } \\
& 4^{a} \text { semana } \\
& 5^{a} \text { semana }
\end{aligned}
$$

Gráfico 1: Pesagem de lixo por semana (\%) no Hospital Regional Dr. Américo Maia de Vasconcelos em Catolé do Rocha - PB, 2013.

Silva (2008), trabalhando com resíduos sólidos patogênicos no Hospital e Maternidade Maria Paulino Lúcio no município de São Bento - PB chegou a resultados muito baixos em comparação com a $4^{\mathrm{a}}$ semana do mês pesquisado desse trabalho que mais produziram resíduos, sendo um total de $410 \mathrm{Kg}$ produzidos no Hospital Reg. Dr. Américo Maia de Vasconcelos na cidade de Catolé do Rocha-PB.

Os resíduos do grupo A (risco biológico) produzidos na unidade hospitalar Maria Paulino Lucio obteve um percentual de 30\% em comparação com a unidade hospitalar Dr. Américo Maia que na $4^{\text {a }}$ semana obteve um percentual de 55,1\%, sendo que as duas unidades de saúde juntas somam um percentual de $85,1 \%$, um número relativamente muito alto sabendo que esse 
tipo de resíduo é muito perigoso não podendo ser descartado como o comum, sem falar nas outras unidades de saúde das cidades vizinhas.

Já os resíduos do grupo E (perfurocortantes) na unidade Maria Paulino Lucio obteve um percentual de apenas 7\%, um número muito baixo em relação a $4^{\mathrm{a}}$ semana que mais produziu resíduos sólidos do hospital Américo Maia que chegou a um percentual de 44,8\% de lixo perfurocortante.

Com esses resultados podemos perceber que o Hospital Regional Dr. Américo Maia de Vasconcelos em Catolé do Rocha é o que mais produz resíduos do grupo A (risco biológico) e grupo E (perfurocortantes), pois se trata de uma unidade que atende toda região diariamente com consultas ambulatoriais, urgência e emergência e cirúrgicas, chegando a um total de 3.000 atendimentos no mês, com isso é de grande preocupação, pois esse lixo produzido na unidade hospitalar de Catolé do Rocha tem destino correto, visto que, é incinerado em João Pessoa-PB, mais as outras unidades de saúde da região não descartam esse lixo de forma correta lembrando que na nossa região foi inaugurado um novo hospital na cidade de Belém de Brejo do Cruz o qual a tendência e só aumentar a produção de lixo hospitalar na região e descartado de forma inadequada.

\section{CONCLUSÕES}

1. Temos que conscientizar mais a população a procurar saber os riscos que o lixo tem antes de descartá-lo inadequadamente;

2. Em unidades de saúde pública o lixo torna-se de maior importância, pois trata-se de lixo infectante que causa sérios danos a saúde humana e ao meio ambiente;

3. A educação ambiental foi de grande importância para os funcionários que trabalham no setor hospitalar;

4. É necessário de um aterro sanitário devidamente licenciado na cidade de Catolé do Rocha - PB, e região polarizada, visto que a partir de 2014 será lei a criação do mesmo em municípios com mais de 50.000 habitantes. 


\section{AGRADECIMENTOS}

Agradecemos principalmente ao grande criador Deus por ter nos dado a oportunidade da realização dessa pesquisa e a Universidade Estadual da Paraíba em nome da Prof ${ }^{a}$. Dr ${ }^{a}$. Fabiana Xavier Costa pelo apoio e paciência.

\section{REFERÊNCIAS}

ABRELPE. ASSOCIAÇÃO BRASILEIRA DAS EMPRESAS DE LIMPEZA PÚBLICA E RESÍDUOS ESPECIAIS. Panorama dos Resíduos Sólidos no Brasil, 2010. Disponível em: <http://www.abrelpe.org.br/Panorama/panorama2010.pdf>. Acesso em: 23 jul. 2013.

ALCÂNTARA, Dércio. Reportagem: Cerca de 70\% dos resíduos sólidos na Paraíba ainda são jogados em lixões. Disponível em: <http://www.dercio.com.br/blog/cerca-de-70dosresiduos-solidos-na-paraiba-ainda-/>. Acesso em: 23 nov. 2013.

BARCELLOS, C. Quem sustenta tanto desenvolvimento? Revista Ciência e Saúde Coletiva. Rio de Janeiro-RJ, v.14, n.6, 2009.

BRAVO, M. D. Construindo alternativas à crise socioambiental contemporânea: Educação Ambiental crítica, transformadora e emancipatória e história oral. Revista Eletrônica Mestrado de Educação Ambiental. Rio Grande do Sul, v.26, 2011.

BESEN, G. R. et al. Resíduos Sólidos: vulnerabilidades e perspectivas.In: SALDIVA, P. et al. Meio ambiente e saúde: o desafio das metrópoles. São Paulo: Ex Líbris, 2010.

(CONAMA) RESOLUÇÃO Nº 316, DE 29 DE OUTUBRO DE 2012. Resolução CONAMA № 316/2012 - Ministério do Meio Ambiente.

DEBONI, F; MELlO, S. S. de; TRAJBER, R. Coletivos jovens de Meio Ambiente e ComVida na Escola: a geração do futuro atua no presente. Revista Brasileira de Educação Ambiental. Cuiabá, n.4, 2009.

FELIX, Rozeli Aparecida Zanon. Coleta seletiva em ambiente escolar. Revista Brasileira de Educação Ambiental. ISSN 1517-1256, v.18, janeiro a junho de 2007.

GONZALES, L. T. V; TONZONI-REIS, M. F. C; DINIZ, R. E. S. Educação ambiental na comunidade: uma proposta de pesquisa-ação. Revista Eletrônica Mestrado em Educação Ambiental, Rio Grande do Sul, v.18, 2007.

GUERRA, S. A Crise Ambiental na Sociedade de Risco. Lex Humana. Petrópolis-RJ, v.1, n.2, 2009. 
Instituto Brasileiro do Meio Ambiente e dos Recursos Naturais Renováveis (IBAMA, 2009).

Disponível:<http://noticias.ambientebrasil.com.br >.Acesso em: 23 Julho de 2013.

Informações baseadas em dados obtidos pelo IBGE (CENSO 2010).

LOPES, T. M; SOSSAE, F. C. Educação Ambiental na EMEF prof.Luís Roberto Salinas Fortes no município de Araraquara (SP);um estudo de caso. Revista Eletrônica Mestrado de Educação Ambiental. Rio Grande do Sul, v.25, 2010.

MAIA, K. M. Impactos Ambientais Causados Pelo Destino do Lixo Patogênico das Unidades de Saúde de São Bento-PB: Um Enfoque Sustentável. Monografia de conclusão de curso, Graduação em Ciências Agrárias, Universidade Estadual da Paraíba, Catolé do Rocha, PB, 2009.

MELO FILHO, J. S; COSTA, F. X; VERAS, M. L, M; SILVA, L. P; DANTAS, V. A. Caracterização dos Resíduos Sólidos Gerados no Cemitério de Catolé do Rocha-PB, Após o dia de finados. In: VIII Encontro Nacional de Licenciatura Plena em Ciências Agrárias|VI Semana de Licenciatura em Ciências Agrárias, Catolé do Rocha-PB.

Currículo, Identidade e Trabalho. Campina Grande: Realize Eventos Científicos LTDA, 2011, p.246-252.

OLIVEIRA, T. P. de; LEMOS R. M. Promovendo a educação ambiental como instrumento de aprendizagem nas escolas no município de Iguaí, Bahia- Revista Eletrônica Mestrado de Educação Ambiental. Rio Grande do Sul, v.26, 2011.

SILVA, M. M. P. da et al. Avaliação sanitária de resíduos sólidos orgânicos domiciliares de municípios do semiárido paraibano. Revista Caatinga, Mossoró, v. 23, n. 2, 2010.

SILVA, M. M. P. da et al. Educação Ambiental; Instrumento para sustentabilidade de Tecnologias para tratamento de Iodos de esgotos. Revista Eletrônica Mestrado de Educação Ambiental. Rio Grande do Sul, v. 23, 2009.

SILVA, M. do S. F. da; JOIA, P. R. Educação ambiental: a participação da Comunidade na Coleta seletiva de resíduos sólidos. Revista Eletrônica da Associação dos Geógrafos Brasileiros. Seção Três Lagoas, n.7, 2008. 